Article

\title{
Marketing Performance Sustainability in the Jordanian Hospitality Industry: The Roles of Customer Relationship Management and Service Quality
}

\author{
Jassim Ahmad Al-Gasawneh ${ }^{1}$, Khalid N. AlZubi ${ }^{2}$, Marhana Mohamed Anuar ${ }^{3, * \mathbb{D}}$, Siti Falindah Padlee ${ }^{3}$, \\ Adnan ul-Haque ${ }^{4}$ (D) and Jumadil Saputra ${ }^{3, *(D)}$
}

check for

updates

Citation: Al-Gasawneh, J.A.; AlZubi, K.N.; Anuar, M.M.; Padlee, S.F.; ul-Haque, A.; Saputra, J. Marketing Performance Sustainability in the Jordanian Hospitality Industry: The Roles of Customer Relationship Management and Service Quality. Sustainability 2022, 14, 803. https:// doi.org/10.3390/su14020803

Academic Editor: Alan Fyall

Received: 28 September 2021

Accepted: 6 January 2022

Published: 12 January 2022

Publisher's Note: MDPI stays neutral with regard to jurisdictional claims in published maps and institutional affiliations.

Copyright: (c) 2022 by the authors. Licensee MDPI, Basel, Switzerland. This article is an open access article distributed under the terms and conditions of the Creative Commons Attribution (CC BY) license (https:// creativecommons.org/licenses/by/ $4.0 /)$.
1 Department of Marketing, Faculty of Business, Applied Science Private University, Amman 11931, Jordan; j_algasawneh@asu.edu.jo

2 Department of Management Information Systems, Faculty of Business, Al-Balqa Applied University, Al Salt 19117, Jordan; khaled.zoubai@bau.edu.jo

3 Faculty of Business, Economics and Social Development, Universiti Malaysia Terengganu, Kuala Nerus 21030, Terengganu, Malaysia; siti.falindah@umt.edu.my

4 Faculty of Business, Yorkville University, 100 Woodside Ln, Fredericton, NB E3C 2R9, Canada; ahaque@yorkvilleu.ca

* Correspondence: marhana@umt.edu.my (M.M.A.); jumadil.saputra@umt.edu.my (J.S.)

\begin{abstract}
This study examines the mediating role of service quality between customer relationship management (CRM) performance dimensions and the marketing performance of Jordanian hotels using resource-based view theory and contingency theory. A self-administered survey was conducted on 162 general managers of hotels in Jordan. The data were analyzed using partial least squares structural equation modelling. The findings of the study indicated that service quality mediated the relationship between the CRM performance dimensions (key customer focus, CRM knowledge management, CRM organization, and CRM-based technology) and the marketing performance of Jordanian hotels. This study provides significant contributions to theory and practice. From a theoretical perspective, this study fills in the literature gaps by providing insights about the mediating role of service quality in the relationship between customer relationship management performance dimensions and marketing performance. For managerial contributions, this study suggested that hotels can enhance their marketing performance by focusing on service quality and customer relationship management performance dimensions, especially the key customer focus dimension.
\end{abstract}

Keywords: key customer focus; CRM knowledge management; CRM organization; CRM-based technology; service quality; marketing performance

\section{Introduction}

Sustainability is a critical concern in the hotel industry worldwide, as well as in Jordan. Over the last few decades, hoteliers have focused on the importance of economic sustainability in the hospitality industry, as it relates to hotel growth and operations. Economic sustainability allows hotels' guests and other stakeholders to gain benefits from the hospitality services [1]. In order to meet the customers' ever-changing needs, hotels can capitalize on the use of technology and service innovation strategies such as customer relationship management (CRM) [2]. The emphasis on meeting customers' needs via innovation and technology is crucial to the hotel industry globally, as well as in Jordan, in order to gain a sustainable competitive advantage. The successful implementation of marketing strategies would be able to enhance marketing performance and the organization as a whole [3].

In the Jordanian hospitality industry, service quality is among the key factors in the attainment of a sustainable competitive advantage, and in gaining the confidence of customers in a competitive marketplace. For this lreason, service quality can impart a 
great opportunity to the hospitality industry, not only in Jordan but worldwide, in order to generate competitive differentiation among organizations. Thus, in this industry, service quality is deemed an important core concept and a critical success factor [4]. Service quality is measurable, and several general scales are available for its measurement. In this regard, SERVQUAL, which is based on the service quality of tangible and intangible dimensions, is among the most popularly employed measurements. According to Al-Ababneh [4] and Zeithaml, Berry and Parasuraman [5], the use of SERVQUAL is convenient in the service and hospitality sector.

The hotel sector is facing a considerable amount of challenges, particularly in regard to marketing performance and customer perception [3,6]. Al-Azzam [7] stated that, since 2012, Jordanian hotels have faced fluctuating and low rates of occupancy. Furthermore, according to the Ministry of Tourism Jordan [8], the number of booked rooms dropped from 4.9 million in 2012 to 3.3 million in 2013, and despite some fluctuation, this decline has continued. This means that within the period between 2012 and 2016, hotels in Jordan experienced roughly a $25 \%$ drop-in booked rooms. At the end of 2019, Jordan's tourism sector boomed, with a $9.4 \%$ increase in total sector revenues, equivalent to USD 4.9 billion. Among the causes for the decline in the occupancy rate in Jordanian hotels was the dissatisfaction felt by hotel customers in the years of 2012 to 2016, which led to poor customer retention and market share, profitability and other factors. This consequently caused a decline in the marketing performance of the hotels [9,10]. Likewise, Al-Adamat [10], Talabi [11], and Hammouri, Al-Gasawneh, Nusairat, Hanandeh and Barakat [12] stressed that hotels in Jordan need to improve their business capability and performance, as well as the marketing performance measure.

Pratminingsih, Astuty and Widyatami [13], and Al-Gasawneh, Anuar, Dacko-Pikiewicz and Saputra [14] revealed the importance of employing business strategies and implementing effective quality strategies for business enhancement. Al-Azzam [7] stated that the hotel sector, especially, seems to be lacking in terms of transparency and quality of service. In this regard, Abu-Nazir, Jadalla and Naseri [15] highlighted the need to improve and sustain service quality through the adoption of long-term relationship strategies, and by placing more focus on the technical quality or the aspects of the service.

Abu-Nazir, Jadalla and Naseri [15] highlighted the need to improve and sustain service quality through the adoption of long-term relationship strategies, and by placing more focus on the technical quality or the aspects of the service. Within the context of hotels, one of the main management and technological strategies for maintaining long-term relationships with customers and improving service quality is CRM [7,16-18]. Furthermore, the marketing performance of hotels needs to be improved by sustaining the long-term relationship with customers through the introduction of special offers and the employment of certain strategies and better information technology (IT) systems such as CRM applications $[7,19,20]$.

Our review of the previous literature suggests that there is a lack of studies that investigated the relationship between CRM performance and marketing performance in the tourism and hotel industry [21,22]. Additionally, very few studies have examined service quality (SERVQUAL) as a mediator between CRM performance and marketing performance in the context of the hotel industry [20]. Therefore, the objectives of this study are (1) to examine the effect of CRM performance on marketing performance, (2) to examine the effect of CRM performance on service quality, (3) to examine the effect of service quality on marketing performance, and (4) to examine the mediating role of service quality on the relationship between CRM performance and marketing performance.

\section{Literature Review}

\subsection{Resource-Based View (RBV) Theory and Contingency Theory}

The resource-based view theory analyses and construes the resources that organizations have in order to comprehend the ways in which organizations attain a sustainable competitive advantage. Barney [21] indicated that at the core of the RBV theory lies the 
notion that each firm possesses inimitable attributes that can act as sources of superior performance and competitive advantage. In this regard, resources that cannot be transferred or purchased without difficulty, or those that would call for a comprehensive learning curve or a drastic transformation in the climate and culture of the organization, would probably be more specific or unique to a particular organization. Such resources would be deemed challenging to replicate. Relevantly, Conner [22] indicated that the performance variance among firms is determined by their ownership of unique inputs and competences. In this regard, the RBV theory proposes that an organization can be viewed as an ensemble of resources, including organizational, physical, and human resources [21,23]. Additionally, Barney [21] stated that, in the achievement of superior performance, the resources of organizations that are deemed to be rare, valuable, hard to replicate and hard to replace constitute the primary source of sustainable competitive advantage. In the assurance of competitive advantage and sustainable performance, a resource must satisfy the valuable, rare, imperfect imitability, and non-substitutability (VRIN) criteria, as detailed below:

- $\quad$ Valuable (V): Valuable resources are those that provide strategic value to a firm. Such resources assist a firm in taking advantage of market prospects, or in easing the reduction of market threats. Notably, the ownership of a resource that does not add or improve to a firm's value would be fruitless.

- $\quad$ Rare (R): Organizations should be in possession of resources that are hard to find among current and potential rivals. It is, therefore, crucial to be in possession of resources that are rare or unique in order to gain a competitive advantage. Possessing resources that several other firms in the marketplace also possess cannot give a competitive advantage because firms cannot devise and employ a business strategy that is unique by using resources that are also held by rivals.

- Imperfect imitability (I): A firm that has resources that have imperfect imitability is at an advantage because rivals cannot copy or imitate those resources easily. Among the attributes associated with imperfect imitability are obstacles to obtaining the resource, an unclear link between competence and competitive advantage, and the intricacy of such a resource. However, the holding of certain resources can only lead to a sustained competitive advantage if their non-possession means and reflects their non-acquirement.

- $\quad$ Non-substitutability $(\mathrm{N})$ : This criterion indicates the impossibility of substituting a given resource with an alternative resource. This means that the use of an alternative resource will not result in the achievement of the exact desired performance. The possession of valuable resources should allow a firm to do things and act in ways that increase sales and margins, and decrease costs, or increase a firm's financial value [21]. Resources can be perceived as carrying value when they allow a firm to perceive or use strategies which lead to better efficiency and effectiveness [21].

Notably, the application of RBV theory allows firm managers to gain an understanding as to why competences are viewable as the most important asset of a firm. At the same time, managers can appreciate how those assets are of value in business performance improvement. As posited by RBV theory, attributes associated with past experiences, organizational culture and competencies are integral to a firm's success [24].

Luthans and Stewart [25] stated that the contingency approach refers to the identification and development of functional relationships between the environment, organization (culture), knowledge management, communication intensity and performance. Sirmon, Hitt, Ireland and Gilbert [26] stated that the contingency view posits that the effectiveness of decision-making is dictated by the competitiveness and structural settings of an organization, and the performance effects of 'fit' thus become the focal point.

The integration of contingency theory and RBV provide an explanation of the relationship among the variables. Based on the contingency theory, environmental factors lead to superior performance. Specifically, in this study, contingency theory explains the effect of CRM performance dimensions (i.e., key customer focus, knowledge management, CRM organization, and CRM-based technology) on marketing performance. Meanwhile, RBV 
theory explains the capability resources as they relate to attaining a competitive advantage. Specifically, the theory explains the effect of CRM performance dimensions (i.e., key customer focus, knowledge management, CRM organization, and CRM-based technology) on service quality, as well as the mediating role of service quality between CRM performance and marketing performance.

\subsection{Research Framework and Hypothesis Development}

2.2.1. Relationship between CRM Performance and Marketing Performance

According to Albakri and Hadi [27] and Martensen and Grønholdt [28], marketing performance refers to a group of activities which are integral to the accomplishment of the strategic objectives of marketing management. Additionally, Drohan, Lynch and Foley [29] stated the need for results quantification in the reporting of the performance level of an organization. In this regard, key performance indicators can be employed by an organization to make sure that it is reaching its goal of demonstrating the expected marketing performance.

The term "CRM" encompasses, on the one hand, a business strategy and, on the other hand, the software that is acquired by companies to manage customer relationships; in the context of companies in the hotel industry, CRM is therefore deemed to be a fitting strategy. According to Zineldin [30], the use of CRM in marketing among hotels facilitates the development of interactive relationships with customers, as well as the ability to fulfil the needs and preferences of individual customers. Within the hospitality industry, CRM is now an important tool, and as mentioned by Madhovi and Dhliwayo [31], CRM is seen as the next most effective management tool after strategic planning. In fact, the applicability of CRM has increased, owing to the increased competition following to the world's recovery from the recent economic slump. Furthermore, Vallabh, Radder and Venter [32] stated that, in a world that is currently very competitive, CRM seems to be among the most imperative strategies to employ in the attainment of competitive advantage.

Past CRM studies have proven that organizations that effectively implement CRM can go on to reap the benefits from CRM, and thereby become better [33,34]. Additionally, Benedettini, Swink and Neely [35] indicated that such customers continue to purchase the same services or products, as well as other related and/or costlier offerings. Furthermore, [36] stated that considering that it costs much less to serve loyal customers, improving customer loyalty and retention would reduce the expenses related to marketing. Indeed, CRM performance was found to positively and significantly affect marketing performance by several previous studies, including that of Soliman [36], who reported a positive link between CRM and marketing performance. In particular, the author indicated that, in financial institutions, CRM dimensions influence marketing performance positively. Relevantly, Shaaban and Ghoneim [37] reported that CRM performance has an impact on a business's marketing performance. Consequently, marketing performance and growth criteria have been drawn. A positive impact of CRM performance on marketing performance was also reported by Albakri and Hadi [27]. Moreover, a similar impact of CRM performance dimensions on marketing performance was also reported by Ewnetu [38], who studied the effect of CRM performance dimensions on marketing performance.

\subsubsection{Relationship between Key Customer Focus and Marketing Performance}

Employee satisfaction, innovation, and customer satisfaction seem to be considerably affected by customer focus [39], and according to Yaacob [40], this results in a better awareness of marketing performance. Additionally, the author reported that the structural model in his study demonstrated that there is an indirect link between customer focus and customer satisfaction. Notably, the author found that customer satisfaction is impacted by employee satisfaction, and employee satisfaction also facilitates the impact of customer focus on inventiveness [41]. In other words, employees' satisfaction, inventiveness, and customer satisfaction greatly affect the attainment of marketing performance. On the other hand, Nwokah [42] found a strong and positive link between the three constructs 
of customer focus, competitor focus and marketing performance. The authors drew two major inferences from their results. The first one is dedicated to scholars concerning the examination of the link between customer focus, competitor focus and marketing performance in two firms. In earlier marketing concept studies, the general assumption was that the application of a key customer focus strategy would result in better marketing performance [43]. This assumption seems to be valid, because a positive significant link between customer orientation and an organization's marketing performance has been reported in a number of studies $[27,44]$. Therefore, the findings of previous studies led to the construction of the first hypothesis:

Hypothesis 1 (H1). Key customer focus has a positive impact on the marketing performance of Jordanian hotels.

\subsubsection{Relationship between CRM Knowledge Management and Marketing Performance}

Knowledge can help a firm to generate value for itself and for its customers as well. Relevantly, knowledge management, also known as KM competency, can assist firms in improving their business approaches and procedures. Moreover, KM facilitates the establishment of an effective CRM system, as it can be used to ensure that the most ideal organizational structure is realized, and that both organizational resources and human resource management are dedicated to achieving this goal. However, in the CRM process, contacting people is generally regarded as the most difficult task. The internal market, therefore, plays an important role in customer-focused customer services delivery, and as described by Akroush, Dahiyat, Gharaibeh and Abu-Lail, [33] and Namjoyan, Esfahani and Haery [45], in any organization it is the result of communication between human resource management and marketing. The relationship between marketing performance and KM was studied by Raeeszadeh, Gilaninia and Homayounfar [46], and they found that marketing performance seems to be significantly and positively affected by KM. Additionally, in their comparative analysis, the authors mentioned that organizations are facing a significant challenge in terms of fully understanding KM and its method of implementation.

Moreover, human resources and KM seem to be positively and significantly linked together; in fact, many KM systems have met with failure because the human aspect was overlooked. Relevantly, a meaningful relationship between customer KM and marketing competencies was reported by Fan and $\mathrm{Ku}$ [46] who found that KM can also significantly empower firms in their strategic decision-making. Moreover, as indicated in some other past studies $[33,47,48]$, firms with successful KM can effectively form positive and superior customer relationships, and such relationships affect marketing performance in a positive manner.

Past studies by Almotairi [49]; Chang, Wang and Arnett [50]; and Ahmad [51] suggested that the positive link between CRM knowledge management and marketing performance is attributable to RBV theory [21]. Meanwhile, in any organization, the importance of knowledge management in CRM as an aspect of CRM performance has also been proposed in a study performed by Alghasawneh, Akhorshaideh, Alharafsheh, Ghasawneh, Al-Gasawneh and Al-Hadid [52]. Furthermore, the positive link between knowledge management (KM) and some variables has been highlighted by several studies, for instance, between KM and market share and customer satisfaction as in Sin, Alan and Yim [44], and between KM and customer satisfaction as in Masa'deh, Almajali, Alrowwad and Obeidat [53]. Therefore, the findings of previous studies led to the construction of the second hypothesis:

Hypothesis 2 (H2). CRM knowledge management has a positive impact on the marketing performance of Jordanian hotels. 


\subsubsection{Relationship between CRM Organization and Marketing Performance}

The impact of CRM organization on marketing performance has been explored by several past works. For instance, from their examination of the effect of CRM on marketing performance, Namjoyan, Esfahani and Haery [45], and Shaaban and Ghoneim [37] concluded that CRM organization affects marketing performance. Meanwhile, the link between CRM organization, marketing competencies and performance was explored by Mohammed and Rashid [54], and they concluded that the capacity of CRM organization plays a role in the implementation of the four dimensions of CRM. Furthermore, according to the authors, CRM implementation leads to better marketing performance. Furthermore, the authors proposed a conceptual model which proves the link between CRM organization that employs CRM dimensions, and marketing performance. As such, in respect to CRM application, an organization's eagerness to change its approach to business procedures becomes a major challenge. Notably, a lot of organizations have expressed a passion for providing the type of customer service that would strengthen their relationship with customers. Nevertheless, as indicated by Akroush, Dahiyat, Gharaibeh and Abu-Lail [33]; Albakri and Hadi [27]; and Wali, Wright, Nwokah and Reynolds [55], organizations have not been making sufficient efforts to do so, and their failure has reduced the effectiveness of CRM implementation, impeding the achievement of improved marketing performance. Therefore, considering the above, the following hypothesis was formulated:

Hypothesis 3 (H3). CRM organization has a positive impact on the marketing performance of Jordanian hotels.

\subsubsection{CRM-Based Technology and Marketing Performance}

The incorporation of technology into marketing components (e.g., product placement, market segmentation, target segment choice, awareness of customer conduct, sales control, marketing campaign management, and market awareness) positively impacts marketing strategy and performance [56]. Due to advances in IT, organizations can conduct comprehensive customer value analysis and provide customized services to customers. This could further enhance the marketing systems development, and could thus greatly contribute to CRM success and marketing performance $[10,44,57]$. The significant positive impact of technology-based CRM on organizational and marketing performance has been reported by a number of studies [33,44,58]. In the context of hotels, Mohammed and Rashid [54] found a significant and positive link between CRM technology and performance. Furthermore, Al-Azzam [7] stated that organizational performance can be improved by such a positive contribution. Therefore, the following hypothesis postulates that:

Hypothesis 4 (H4). CRM-based technology has a positive impact on the marketing performance of Jordanian hotels.

\subsection{Relationship between CRM Performance and Service Quality}

Past studies on service quality are expansive, especially regarding its measurement in diverse private and public sectors all over the world, and the sectors that have most commonly been covered are the airline, banking, hotel and restaurant sectors. In the current environment of global economic decline, marketing performance and service quality seem to be the most important factors for the retention, productivity and profitability of businesses in general. Consequently, the contribution of service quality seems to be the most crucial factor to consider in any investigation of the outcomes of business services as expected and perceived by the customer [59]. In this regard, Allon and Babich [60] stated that service quality is of the utmost importance for both the customers and the companies in the manufacturing, service and retail sectors.

Past studies have found a positive association between CRM performance and service quality in the banking industry and educational institutions [7,16]. Moreover, the authors found that service quality and CRMP dimensions (i.e., key customer focus, CRM organiza- 
tion, KM, and technology-based CRM) are significantly and positively linked. According to Wali, Uduma and Wright [61], the relationship between CRM and service quality in educational institutions (universities) seems to be positive and significant. Meanwhile, in Jordan's banking sector, Huang, Ho and Chen [6] affirmed that there is a strong relationship between CRM and service quality. The authors further indicated that CRM significantly affects the service quality of Jordanian hotels.

\subsubsection{Relationship between Key Customer Focus and Service Quality}

Ryding [62] indicated that the currently turbulent business environment and intensifying customer influence compel organizations to employ customer-focused strategies, especially those that involve the application of innovative technology to form customer relationships. Furthermore, as today's business environment has changed into one that is becoming increasingly aggressive, Ngo and Nguyen [63] argued that there is a need for organizations to opt for customer-focused strategies that foster the positive significance of paradigms linked to customers, including service quality, customer satisfaction, and customer loyalty. The authors further stated that such an approach would increase performance. Meanwhile, Irfan and Kee [64] empirically tested the link between key customer focus and service quality. The authors used the structural equation modelling (SEM) approach to test the relationships of the criteria. The results showed that there is a significant positive association between the two constructs. Similarly, Ghandour, Deans and Benwell [65], and Abd Rahim Romle, Zakaria, Zakinuddin, Zolkepli and Daud [66] also concluded that there is a positive link between key customer focus and service quality. These studies further stated that customers' opinions can enhance the services that a company provides. Hence, in light of the above, the following hypothesis was proposed:

Hypothesis 5 (H5). Key customer focus has a positive impact on the service quality of Jordanian hotels.

\subsubsection{Relationship between CRM Knowledge Management and Service Quality}

Organizations could benefit from the knowledge of customers, as this knowledge could be used in the formation of new concepts, and in the continuous improvement of the provided services or products. Such knowledge could also assist organizations in improving their efficiency and reputation. Accordingly, Azhar [67] indicated the importance of increasing and pledging service quality along with customer knowledge, because these factors could all help organizations to fulfill customer requirements, particularly in terms of service effectiveness.

The obtained results showed that Knowledge Management (KM) has a positive effect on both CRM and service quality. The authors also found that CRM has a positive impact on service quality. In the context of hotels, Lo, Stalcup and Lee [68] proposed that new knowledge concerning present and potential customers needs to be acquired in order to improve service quality. Moreover, the authors stated that such knowledge must be dispersed throughout the entire organization. In line with the above, Torbati, Jokar and Liravi [69] reported that KM has a positive and significant impact on service quality improvement, and the authors additionally highlighted that diverse KM dimensions impact service quality improvement the most. Similarly, it was reported by Goldman, Harris and Omer [70] that the link between KM and service quality is positive, but varies based on the accessibility of expert professionals. Meanwhile, the outcomes of a multiple linear regression analysis presented in Khafajy, Alzoubi and Aljanabee [71] demonstrated that KM processes have a positive significant impact on service quality dimensions in the context of banking, implying that an increase in interest among the management of commercial banks in all KM processes could facilitate the improvement of the service quality in this sector. Therefore, based on the above literature, the following hypothesis was constructed:

Hypothesis 6 (H6). CRM knowledge management has a positive impact on the service quality of Jordanian hotels. 


\subsubsection{Relationship between CRM Organization and Service Quality}

In guiding organizations in their accomplishment of goals and a sustainable competitive advantage, Asgari and Omrani [16] highlighted the importance of the management and organization of the company by the organization managers. For the managers of these organizations, the authors indicated the importance of increasing their capacities in this domain. Managers need to be well versed in organizational strategy, and to provide an easy, updated and interactive environment in order to allow the sharing and management of knowledge among the various parties in the organization. The application of CRM in organizations undeniably affects service quality in a positive manner. Among organizations, there seems to be a general tendency to follow approaches that allow them to achieve a competitive advantage over their opponents, as can be observed from their use of approaches that promote organization and their focus on internal service quality. Accordingly, Pasebani, Mohammadi and Yektatyar [72] mentioned that service quality is among the crucial elements that facilitate efficiency in a dynamic and changing organization, and that organizational culture and internal service quality seem to have a positive and significant correlation with each other. Similarly, in the context of healthcare organizations, Habidin, Ali, Janudin, Zainol, Mustaffa and Hudin [73] mentioned the importance of patient focus as a factor of organizational success. Notably, there seems to be a difference in the viewpoints of healthcare providers and patients, because patients make their own judgements about the services they receive. In fact, it is challenging to satisfy the expectations of patients even when a healthcare provider provides them with various facilities and services. Hence, the provision of a service that is superior to what the patient expects can help the healthcare provider to improve their service quality. Essentially, CRM can be described as a strategy that organizations employ to retain their customers and maintain a good relationship with their customers. Hence, the following hypothesis was constructed:

Hypothesis 7 (H7). CRM organization has a positive impact on the service quality of Jordanian hotels.

\subsubsection{Relationship between CRM-Based Technology and Service Quality}

Kotler and Armstrong [74] claimed that the proliferation of IT-centred services has led customers to expect the consistent provision of higher service quality. The link between technology-empowered service delivery and electronic or web-based service quality has been highlighted by several prior studies, including Collier and Bienstock [75], and Zeithaml, Berry and Parasuraman [5]. Regarding the use of technology-based services, Ombati, Magutu, Nyamwange and Nyaoga [76], in their study on the situation in Arusha, provided an example of the use of kiosks with touch screens that customers can use to request takeout food. Another example is the provision by banks of the use of wide networks of automated teller machines in offering customers numerous banking services. In the case of telecommunications companies, the authors concluded that the link between technology-based CRM and service quality is affected by microenvironmental factors. The authors additionally stressed the importance of service-based companies in establishing strategies to appropriately adapt to the external environment. In a study that attempted to understand the impact of technology-based CRM on service quality, Foya, Kilika, Muathe and Herman Foya [77] found that technology-based CRM has a positive impact on service quality. Furthermore, in two works that examined the manners in which technology impacts agents' incentives, and subsequently service quality, Malkawi [78] showed that the concept of a moral hazard among taxi and Uber drivers in respect to the performance of route detours led to a positive effect of technology on service quality. In light of the findings in the reviewed literature on the effect of technology on service quality, the following hypothesis was developed:

Hypothesis 8 (H8). CRM-based technology has a positive impact on the service quality of Jordanian hotels. 


\subsection{Relationship between Service Quality and Marketing Performance}

Bowie, Buttle, Brookes and Mariussen [79], and Chumpitaz and Paparoidamis [80] stated that service quality drives the economic and marketing performance of the organization. Furthermore, the issue of service quality in the government sector was studied by Akroush [81]. The authors reported that in this sector, particularly in developing nations, increasing importance is being placed on the quality of the services provided. The service quality and marketing performance were measured, and a positive significant relationship between service quality and marketing performance was noted by the authors. Based on the discussions and results in previous studies on service quality, the following hypothesis was formulated:

Hypothesis 9 (H9). Service quality has a positive impact on the marketing performance of Jordanian hotels.

\subsection{The Mediating Role of Service Quality}

Ferreira and Fernandes [82] stated that there is a lack of studies regarding the exploitation of resources and capabilities that can contribute to the resolution of arising problems, considering the conditions under which the capability resource value and awareness combination contribute to firms' performance levels. The authors further stated that the studies on the effect of the competitive advantage in this relationship are also insufficient. Furthermore, from the perspective of Amit and Schoemaker [23], resources require use and/or exploration in an efficient manner in order to build up capacities. Thus, a determined resource may have the potential to contain a valuable service, but this service will only ever remain latent prior to its utilization through the means of a relevant capacity. Furthermore, according to Newbert [83] and Barney [21], the resource-based view theory (RBV) stated that whenever a combination of resources/capacities is proven, companies may then attain a competitive advantage, before highlighting how the rarer respective combinations could result in greater returns to the company in terms of competitive advantage and performance. Amit and Schoemaker [23] also revealed that the resources require use and exploration in efficient manners in order to build up capacities. Thus, a determined resource may have the potential to contain a valuable service for the purpose of building the capacities and linkage between the resources/capabilities and performance.

According to Baron and Kenny [84], a mediator variable is a variable that reveals the association between a predictor variable and a criterion variable. Mediators inform how or why something works. Furthermore, the mediator is considered to be an intervening variable which illustrates the association among a predictor variable and a criterion variable. The conditions to assume any variable as a mediator $(\mathrm{M})$ are through testing it between two variables, $X$ and $Y$. Mediators are persistent in the relationship between the variables, as proven through the previous studies in which the researchers had to find previous literature that presented a positive impact between the independent variable $(X)$ and dependent variable $(\mathrm{Y})$, as well an appositive impact between the independent variable $(\mathrm{X})$ and mediator $(\mathrm{M})$, and likewise, a positive impact between the mediator $(\mathrm{X})$ and the dependent variable $(\mathrm{Y})$. In case the literature supports these relationships, you can use the $\mathrm{M}$ as a mediator in the research to test it. As for the service quality, there were some studies that tested it as a mediator between different variables, and the field of this study that found so is as shown below.

Osarenkhoe, Birungi Komunda and Mbiito Byarugaba [85] found that service quality mediated the relationship between customer complaint behaviour and customer loyalty. Furthermore, Akroush [86] concluded that service quality plays a mediating role in the relationship between technical quality and bank performance. Similar findings were also discovered in a study conducted by Manohar [87], who revealed that service quality mediated the link between service innovation and customer word of mouth. Furthermore, Alghamdi and Bach [56] stated that the use of service quality, as a mediator variable, was 
a means to intensify the strength of the positive association between internal marketing dimensions as the independent variable and job satisfaction as the dependent variable.

Based on the previous relationships that mentioned the relationship between variables that are similar to this study and the mediator usage conditions, the current study will examine service quality as a mediator in the relationship between CRMP dimensions (key customer-focus, CRM knowledge management, CRM organization, CRM-based technology) and marketing performance in Jordanian hotels. The proposed research framework as presented in Figure 1. Also, the study hypotheses were formulated:

Hypothesis 10 (H10). Service quality mediates the relationship between the key customer focus and marketing performance of Jordanian hotels.

Hypothesis 11 (H11). Service quality mediates the relationship between the CRM knowledge management and marketing performance of Jordanian hotels.

Hypothesis 12 (H12). Service quality mediates the relationship between the CRM organization and marketing performance of Jordanian hotels.

Hypothesis 13 (H13). Service quality mediates the relationship between the CRM-based technology and marketing performance of Jordanian hotels.

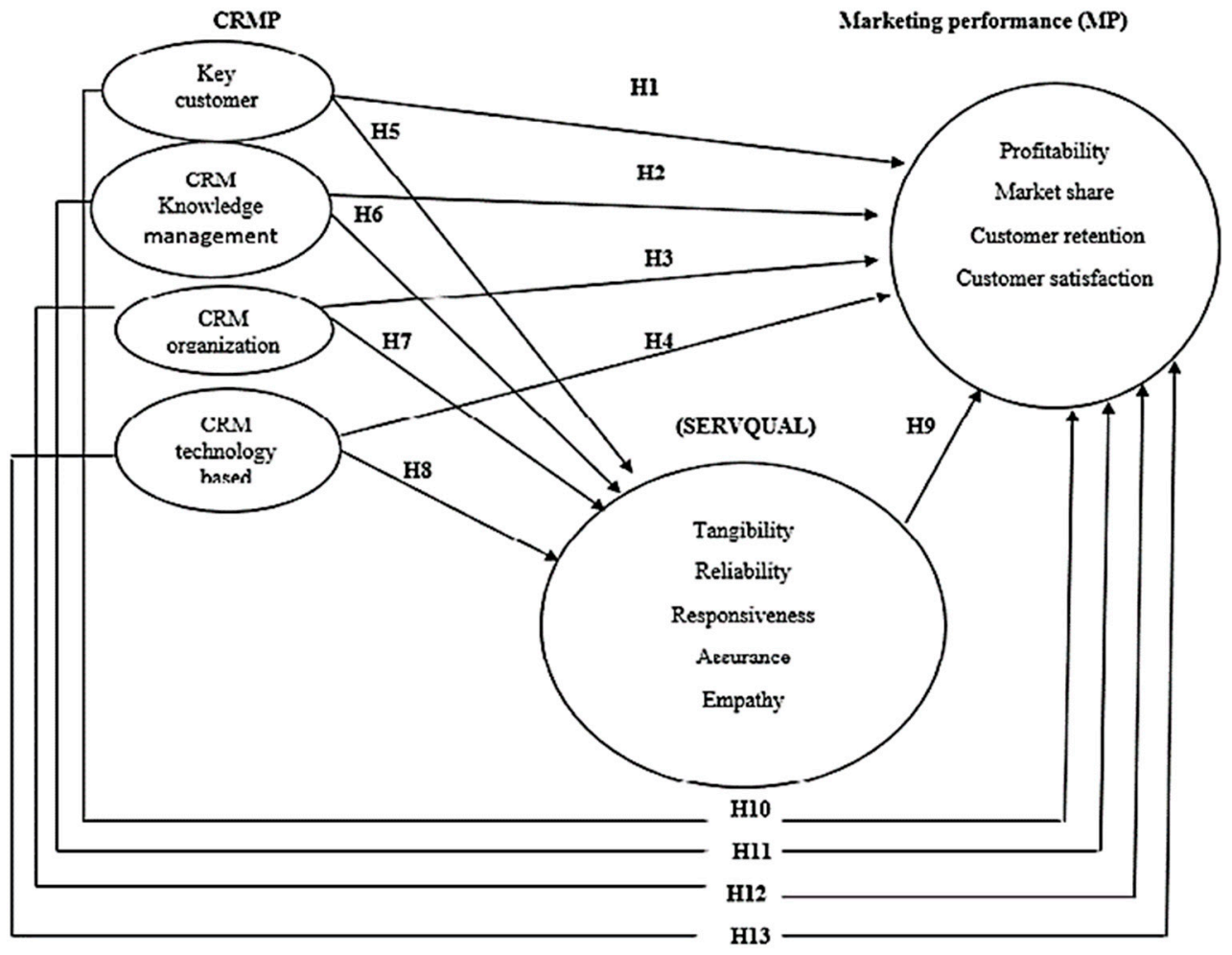

Figure 1. Research framework.

\section{Materials and Methods}

\subsection{Research Design}

The current research is descriptive in its nature. Primary data were collected for the current study. The current research was cross-sectional, as the research data were collected on a one-time basis to provide answers to the research questions [88]. The collection of the research data was performed through self-administrative survey, in order to obtain a good grasp of whether or not service quality acts as a mediator between CRM performance and marketing performance among the general managers in Jordanian hotels. In order 
to ensure variable consistency and prevent confusion among the targeted respondents, this study adopted a five-point Likert scale to measure all of the responses provided by the respondents.

\subsection{Population and Sample}

In Jordan, hotels are divided into five categories [8]: one-star, two-star, three-star, fourstar and five-star. The categories are determined by a formula that includes factors such as the facilities and average daily rate (ADR). This categorization is backed by substantial differences in the ADR and the number of employees in each room. According to Ministry of Tourism Jordan [8], 236 hotels were rated as one- to five-star at the time of the study. Moreover, general managers are deemed to know about CRM performance, service quality, and marketing performance within their firm, as evidenced by their capability of answering almost all the questions posed on these issues $[4,19,44,89]$. Hence, the current study followed the key-informant methodology by selecting hotel managers as the informants.

We determined the population of 236 hotels, which is represented by general managers as a sample. This study followed the G-power software statics method to determine the sample size, where the 92 samples were determined as a minimal sample size after applying the following rules: an F-statistical test, an error probability of 0.05 (meaning a power level of $1-\beta=0.95$ ), a power standard of 0.80 , and a moderate effect size; then, there were five predictors in this study [90]. However, in order to ensure that the minimum number of the responses would be obtained, and taking into consideration that the survey method has a weak response rate, the minimum number of the respondents needed to be analysed has to be more than 100 questionnaires [91]. With an added 120 questionnaires to the minimum sample size 92, a total of 212 questionnaires were distributed in this study in order to obtain a more accurate result, where a $5 \%$ margin of error has been taken into consideration. With regard to the sampling technique, the current study applied stratified sampling to the hotel categories. Then, the researcher proceeded to the next phase, which involved the selection of the hotels (respondents) by different categories. For each category, a simple random sampling technique was used to select the hotel respondents.

\subsection{Research Instruments}

The questionnaire developed for this study consisted of four main sections: Section A contained questions to obtain general demographic information on the respondents, including gender, age, education, and working experience, and thus consisted of six items. Section B was the independent variables, focusing on the CRMP dimensions and comprising four subsections covering the following: key customer focus (KCF), CRM knowledge management (KLM), CRM organization (ORG), and technology-based CRM (TKB); each of the subsections contained five items that were adapted from $[14,19,44]$. Section $C$, as the mediator, addresses the issue of service quality (SERVQUAL), and contained five subsections covering the elements of tangibility, reliability, responsiveness, assurance, and empathy; there were four items in each of these five subsections, which were adapted from $[4,5,86]$. Finally, the last section of the study instrument, Section D, the dependent variables, concerned the marketing performance (MP) and comprised four subsectionscustomer satisfaction, customer retention, market share, and profitability-which were adapted from $[27,92,93]$.

\subsection{Pre-Test}

After having prepared the measurement items and prior to the main data collection, it is necessary to test the validity of the questionnaire in order to ensure that it would be effective in terms of exactly measuring what it was supposed to measure. Therefore, the current study conducted two phases of pre-testing, with these being the first phase that was conducted between August and November 2017, which involved asking an expert panel of three academicians to assess the questionnaire. The questionnaire was reviewed by these three experts, and their comments were taken into consideration. The next phase of 
pre-testing, as mentioned by Akroush, Al-Mohammad and Odetallah [94], was conducting the pilot test through the interviewing of a small population size that is appropriate and adequate. For this study, we pre-tested the questionnaire through interviews with 30 respondents, who were managers that represented 30 rated hotels from one to five stars in Jordan. This was carried out to ensure that the questions in the study instrument were adequate, good, clear, reasonable, and understood in relation to the purpose of the study.

\subsection{Data Collection}

The back-translation process was constructed in order to translate the questionnaire to Arabic and then return it to English, because the English language is not used as an official language in Jordan [95]. This was carried out in order to ensure that it would be well understood by the respondents. Then, the study employed a self-administered survey (drop and collect), which is defined as a method of distributing the questionnaire to the people in their work where the respondents have to fill it in at work or take it to home with them, without the presence of the questionnaire distributor/interviewer [96]. In order to differentiate the responses, the hotel rating classification was written on the questionnaire cover. Then, the study used a statistical remedy to address the issue of CMV Harman's single factor test, in order to make sure that there is no bias in the respondents' responses.

\subsection{Data Analysis}

Two software programs were used in the data analysis: SPSS-23 and PLS-SEM version 3.2.8. First, descriptive statistics were used to determine the response rate, the demographic profile of the respondents, and the response bias. The PLS-SEM software was used to obtain inferential statistics in order to test for outliers, and to assess the measurement model and the structural model. The reasons for using PLS were to analyze the study framework: PLS-SEM has been reported to account for measurement errors, and can yield better estimates of mediating effects. It is also more beneficial to use PLS when researchers are faced with complex models, as the PLS software handles non-normal data well.

\section{Results}

\subsection{Data Screening and Descriptive Statistics}

A total of 212 questionnaires were distributed, out of which 172 were returned from the hotels that adopted customer relationship management performance; this represents a response rate of $81 \%$. However, 10 questionnaires were invalid because they were incomplete, giving a final total of 162 valid questionnaires. Nevertheless, there were enough valid questionnaires to conduct further analysis. The male respondents accounted for $122(75 \%)$ of the valid responses, while the female respondents accounted for $40(25 \%)$. Therefore, the male gender was predominant in the study sample. The respondents were asked to provide their age, and the results showed that none of them were less than 30 years old, $7 \%$ were $31-40$ years old, $66 \%$ were $41-50$ years old, $17 \%$ were $51-60$ years old, and $10 \%$ were 61 years old or more. Regarding marital status, $24 \%$ of the respondents were single and $76 \%$ were married. The respondents were also asked to provide their highest level of education. From the results, respondents with a high school certificate accounted for $5 \%$ of the responses, $11 \%$ had a diploma, 56\% had a Bachelor's degree, $27 \%$ had a Master's degree and 1\% had a PhD. As for working experience, 13\% of the respondents had 5 years or less, 19\% had 6-10 years, 28\% had $11-15$ years, 29\% had 16-20 years, and $11 \%$ had 21 years or more.

Finally, regarding the category of hotel in which the respondents were currently working, $25 \%, 31 \%$, and $18 \%$ of the respondents were employees of one-, two-, and threestar hotels, respectively, while $14 \%$ and $12 \%$ were working in four- and five-star hotels, respectively. From the screening results, there was a small percentage of missing data. Hence, for each item, the missing data were replaced with the variable median response. Furthermore, there was no univariate outlier in 162 cases because all of the variables had a score ranging from -2.391 to 2.351 . Likewise, no item exceeded \pm 4 ; in addition, the 
skewness of the variables ranged from -0.568 to 0.060 , while the kurtosis values were between -1.009 and -0.455 . Hence, all of the variables had skewness and kurtosis values that were \pm 2 and \pm 7 , respectively. Therefore, it can be said that the data was well modelled, with a normal distribution. As for the CMV, the results showed that when all 60 items were loaded into one general factor, the first unrotated factor captured only $39 \%$ of the variance in the data. This indicates that CMV likely did not affect the results.

The mean was applied as a measure of the central tendency, Table 1 indicated that except for Assurance (ASU), the mean values of all of the constructs were above their midpoint level of 3 . The constructs with mean values above the midpoint level of 3 indicated that the consensus respondents' perception toward these constructs was above the average. The highest mean rating belonged to Key Customer Focus (KCF), with the mean value of 3.43. The lowest mean rating belonged to Assurance (ASU), with the mean value of 2.99.

Table 1. Results of the descriptive statistics for the variables.

\begin{tabular}{lcc}
\hline \multicolumn{1}{c}{ Constructs } & Mean & Standard Deviation \\
\hline Key Customer Focus (KCF) & 3.430 & 1.076 \\
CRM Organization (ORG) & 3.374 & 1.223 \\
CRM Knowledge & 3.271 & 0.961 \\
Management (KLM) & 3.252 & 0.942 \\
Technology Based CRM (TKB) & 3.120 & 0.693 \\
Service Quality (SERVQL) & 3.056 & 0.818 \\
Tangibility (TNG) & 3.26 & 0.852 \\
Reliability (RLB) & 3.002 & 0.804 \\
Responsiveness (RSP) & 2.99 & 0.69 \\
Assurance (ASU) & 3.285 & 0.901 \\
Empathy (EMP) & 3.200 & 0.731 \\
Market Performance (MP) & 3.136 & 0.858 \\
Profitability (PRF) & 3.197 & 0.842 \\
Market Share (MKS) & 3.147 & 0.887 \\
Customer Retention (CSR) & 3.224 & 0.863 \\
Customer Satisfaction (CSS) & & \\
\hline
\end{tabular}

\subsection{Measurement Model}

The current study pursued a two-stage approach that involved using the first-order construct as an indicator for the second-order construct, and extracting the AVE and CR for the higher-order construct (HOC) [97]. According to Becker, Klein and Wetzels [97], the two-stage approach is advantageous because it does not require an equal number of indicators for the lower-order constructs (LOCs), and yet it can still provide reliable results. Furthermore, this type of approach is recommended when the multidimensional variables (HOC) are endogenous or mediating variables [97]. In the current study, there were two multidimensional variables (HOCs), namely service quality (SERVQUAL) and Marketing Performance (MP), which are the service quality as a mediator and marketing performance as the endogenous or dependent variable (DV).

The two-stage approach was implemented in line with Becker et al. [97]. In the first stage, the repeated indicator approach was implemented, through which the first-order scores were associated with first-order constructs; in the second stage, the weighting of the first-order variables was used to estimate the second-order contract's CRAVE. Moreover, the study includes an overall CFA model (HOC and LOC). The development of each of the measurement models is discussed in the next subsection.

\subsubsection{Construct Validity and Reliability}

The basic concept of SEM analysis is to select the items that will be used to measure the constructs. Each of the constructs in the CFA models was evaluated for its validity and reliability. The reliability of a construct is assessed using Cronbach's alpha, outer loading, AVE, and CR, while DSV is issued to assess the validity of a construct. 
Table 2 shows the initial standardized factor loadings of the model items ranging from 0.727 to 0.953 ; hence, they were all greater than the suggested threshold value of 0.7 [98]. The table also shows that the AVE values ranging from 0.630 to 0.780 ; they were, therefore, all higher than the recommended threshold value of 0.5 [98]. In addition, the CR values were also more than the recommended threshold value of 0.7 [91], as they ranged from 0.872 to 0.947 . Finally, the Cronbach's alpha values ranged from 0.803 to 0.957 , so they were greater than the 0.7 threshold value recommended by Hair, Risher, Sarstedt and Ringle [98].

Table 2. The results of the construct validity and reliability for the first order.

\begin{tabular}{|c|c|c|c|c|c|}
\hline \multirow{2}{*}{ Construct/First Order } & \multirow{2}{*}{ Item } & \multirow{2}{*}{ Loadings } & \multirow{2}{*}{ CR } & \multirow{2}{*}{ AVE } & \multirow{2}{*}{$\begin{array}{c}\text { Cronbach's } \\
\text { Alpha }\end{array}$} \\
\hline & & & & & \\
\hline \multirow{5}{*}{ Key customer focus } & KCF1 & 0.889 & \multirow{5}{*}{0.947} & \multirow{5}{*}{0.780} & \multirow{5}{*}{0.930} \\
\hline & KCF2 & 0.875 & & & \\
\hline & KCF3 & 0.867 & & & \\
\hline & KCF4 & 0.873 & & & \\
\hline & KCF5 & 0.912 & & & \\
\hline \multirow{5}{*}{ CRM knowledge management } & KLM1 & 0.854 & \multirow{5}{*}{0.923} & \multirow{5}{*}{0.705} & \multirow{5}{*}{0.895} \\
\hline & KLM2 & 0.853 & & & \\
\hline & KLM3 & 0.833 & & & \\
\hline & KLM4 & 0.827 & & & \\
\hline & KLM5 & 0.832 & & & \\
\hline \multirow{5}{*}{ CRM organization } & ORG1 & 0.873 & \multirow{5}{*}{0.946} & \multirow{5}{*}{0.778} & \multirow{5}{*}{0.957} \\
\hline & ORG2 & 0.953 & & & \\
\hline & ORG3 & 0.838 & & & \\
\hline & ORG4 & 0.788 & & & \\
\hline & ORG5 & 0.948 & & & \\
\hline \multirow{5}{*}{ CRM based-Technology } & TKB1 & 0.806 & \multirow{5}{*}{0.918} & & \\
\hline & TKB2 & 0.840 & & & \\
\hline & TKB3 & 0.854 & & 0.692 & 0.889 \\
\hline & TKB4 & 0.839 & & & \\
\hline & TKB5 & 0.819 & & & \\
\hline & TNG1 & 0.839 & & & \\
\hline Tangibility (TNG) & TNG2 & 0.870 & 0904 & 0782 & 0858 \\
\hline rangiominty (ING) & TNG3 & 0.847 & 0.904 & 0.702 & 0.858 \\
\hline & TNG4 & 0.792 & & & \\
\hline & RLB1 & 0.853 & & & \\
\hline & RLB2 & 0.860 & & & \\
\hline Reliability (RLB) & RLB3 & 0.867 & 0.909 & 0.714 & 0.866 \\
\hline & RLB4 & 0.797 & & & \\
\hline & RSP1 & 0.839 & & & \\
\hline & RSP2 & 0.856 & & & \\
\hline Responsiveness (RSP) & RSP3 & 0.840 & 0.901 & 0.695 & 0.854 \\
\hline & RSP4 & 0.798 & & & \\
\hline & ASU1 & 0.806 & & & \\
\hline Assurance (ASU) & ASU2 & 0.825 & & & \\
\hline Assurance (ASU) & ASU3 & 0.813 & 0.872 & 0.630 & 0.803 \\
\hline & ASU4 & 0.727 & & & \\
\hline & EMP1 & 0.835 & & & \\
\hline & EMP2 & 0.884 & & & \\
\hline Empathy (EMP) & EMP3 & 0.890 & 0.923 & 0.750 & 0.889 \\
\hline & EMP4 & 0.855 & & & \\
\hline & PRF1 & 0.844 & & & \\
\hline & PRF2 & 0.859 & & & \\
\hline Profitability (PRF) & PRF3 & 0.854 & 0.932 & 0.733 & 0.909 \\
\hline & PRF4 & 0.872 & & & \\
\hline & PRF5 & 0.851 & & & \\
\hline & MKS1 & 0.862 & & & \\
\hline & MKS2 & 0.873 & & & \\
\hline Market share (MKS) & MKS3 & 0.857 & 0.925 & 0.711 & 0.898 \\
\hline & MKS4 & 0.856 & & & \\
\hline & MKS5 & 0.764 & & & \\
\hline
\end{tabular}


Table 2. Cont.

\begin{tabular}{|c|c|c|c|c|c|}
\hline \multirow{2}{*}{ Construct/First Order } & \multirow{2}{*}{ Item } & \multirow{2}{*}{ Loadings } & \multirow{2}{*}{ CR } & \multirow{2}{*}{ AVE } & Cronbach's \\
\hline & & & & & Alpha \\
\hline \multirow{5}{*}{ Customer retention (CSR) } & CSR1 & 0.825 & \multirow{5}{*}{0.923} & \multirow{5}{*}{0.705} & \multirow{5}{*}{0.895} \\
\hline & CSR2 & 0.823 & & & \\
\hline & CSR3 & 0.858 & & & \\
\hline & CSR4 & 0.841 & & & \\
\hline & CSR5 & 0.850 & & & \\
\hline \multirow{5}{*}{ Customer satisfaction (CSS) } & CSS1 & 0.816 & \multirow{5}{*}{0.922} & \multirow{5}{*}{0.702} & \multirow{5}{*}{0.894} \\
\hline & CSS2 & 0.829 & & & \\
\hline & CSS3 & 0.851 & & & \\
\hline & CSS4 & 0.879 & & & \\
\hline & CSS5 & 0.813 & & & \\
\hline
\end{tabular}

Table 3 displays the initial standardized factor loadings of the model items ranging from 0.727 to 0.953 ; they were all greater than the suggested threshold value of 0.7 [98]. The table also shows that the AVE values ranging from 0.630 to 0.780 ; they were, therefore, all higher than the recommended threshold value of 0.5 [98]. In addition, the CR values were also more than the recommended threshold value of 0.7 [91], as they ranged from 0.872 to 0.947 . Finally, the Cronbach's alpha values ranged from 0.803 to 0.957 , so they were greater than the 0.70 threshold value recommended by Hair et al. [98].

Table 3. The results of the construct validity and reliability for the second order.

\begin{tabular}{cccccc}
\hline $\begin{array}{c}\text { Construct/First } \\
\text { Order }\end{array}$ & Item & Loadings & CR & AVE & Cronbach's \\
\hline \multirow{2}{*}{ Service } & Tangibility & 0.898 & & & \\
quality & Reliability & 0.857 & & \\
& Responsiveness & 0.840 & 0.930 & 0.728 & 0.949 \\
& Empathy & 0.891 & & & \\
& Assurance & 0.776 & & & \\
Marketing & Profitability & 0.861 & & 0.949 \\
performance & Satisfaction & 0.875 & 0.910 & \\
& Market share & 0.758 & & & \\
& Customer & 0.889 & & & \\
\hline
\end{tabular}

\subsubsection{Discriminant Validity}

In order to measure the discriminant validity, the current study found out the HTMT for the overall model, including Key customer focus, CRM knowledge management, CRM organization, CRM based- Technology service quality, marketing performance.

Table 4 describes all the HTMT values of the latent constructs in the overall model variables ranged from 0.080 to 0.821 , and were thus below the threshold value of 0.90 . This result proved that each latent construct measurement was totally discriminatory [99].

\subsection{Structural Model}

In the current study, the PLS technique and bootstrapping were used to estimate the structural model with 1000 replications in order to investigate the study hypotheses. This involved five sets of tests to evaluate the R2, F2, Q2, GoF, VIF, and $p$-value of the inner model [98].

Table 5 shows that the $\mathrm{R}^{2}$ values for SERVQUAL and MP were 0.512 and 0.0.684, respectively, suggesting that approximately $68 \%$ of the variance in MP was explained by its five predictors (KCF, KLM, ORG, TKB, and SERVQUAL). In addition, the overall results showed that the $R^{2}$ values met the 0.19 threshold value suggested by Chin [100]. Furthermore, the $\mathrm{F}^{2}$ values for the five predictors KCF, KLM, ORG, TKB, and SERVQUAL were $0.108,0.021,0.026,0.050,0.098$, respectively, which indicated the extent to which each of the five predictors explained the MP. Moreover, the $\mathrm{Q}^{2}$ values for SERVQUAL and MP 
were 0.241 and 0.321 , respectively. These values are above 0 , suggesting that the model has predictive relevance [100]. Generally, the model showed an acceptable level of fitness and high predictive relevance, while the VIF values ranged from 1.070 to 3.156 for the inner model, which were less than 5 [98].

Table 4. The results of the discriminant validity testing using Heterotrait-Monotrait (HTMT).

\begin{tabular}{|c|c|c|c|c|c|c|c|c|c|c|c|c|c|c|c|}
\hline & \multicolumn{2}{|c|}{ Construct1 } & 2 & 3 & 4 & 5 & 6 & 7 & 8 & 9 & 10 & 11 & 12 & 13 & 14 \\
\hline 1 & $\mathrm{KCF}$ & & & & & & & & & & & & & & \\
\hline 2 & KLM & 0.784 & & & & & & & & & & & & & \\
\hline 3 & PRF & 0.776 & 0.761 & & & & & & & & & & & & \\
\hline 4 & MKS & 0.651 & 0.639 & 0.792 & & & & & & & & & & & \\
\hline 5 & CSR & 0.799 & 0.682 & 0.228 & 0.734 & & & & & & & & & & \\
\hline 6 & CSS & 0.231 & 0.764 & 0.694 & 0.792 & 0.572 & & & & & & & & & \\
\hline 7 & $\mathrm{MP}$ & 0.335 & 0.609 & 0.735 & 0.228 & 0.779 & 0.678 & & & & & & & & \\
\hline 8 & ORG & 0.346 & 0.611 & 0.08 & 0.694 & 0.734 & 0.681 & 0.739 & & & & & & & \\
\hline 9 & SRQ & 0.675 & 0.601 & 0.67 & 0.789 & 0.626 & 0.053 & 0.727 & 0.496 & & & & & & \\
\hline 10 & TNG & 0.662 & 0.398 & 0.103 & 0.735 & 0.607 & 0.619 & 0.562 & 0.511 & 0.478 & & & & & \\
\hline 11 & RLB & 0.436 & 0.479 & 0.753 & 0.08 & 0.783 & 0.631 & 0.706 & 0.717 & 0.201 & 0.65 & & & & \\
\hline 12 & RSP & 0.698 & 0.712 & 0.789 & 0.67 & 0.75 & 0.761 & 0.738 & 0.722 & 0.37 & 0.734 & 0.796 & & & \\
\hline 13 & ASU & 0.223 & 0.543 & 0.673 & 0.706 & 0.748 & 0.037 & 0.545 & 0.749 & 0.499 & 0.411 & 0.338 & 0.679 & & \\
\hline 14 & EMP & 0.59 & 0.71 & 0.699 & 0.68 & 0.188 & 0.715 & 0.665 & 0.299 & 0.712 & 0.798 & 0.467 & 0.345 & 0.739 & \\
\hline
\end{tabular}

Table 5. Coefficient determination, effect size and predictive relevance.

\begin{tabular}{cccc}
\hline Path & R Square & F Square & Q Square \\
\hline KCF -> MP & 0.684 & 0.108 & 0.321 \\
KCF -> SERVQUAL & 0.512 & 0.098 & 0.241 \\
\hline
\end{tabular}

Table 6 shows that the direct effects of the CRMP dimensions (KCF, KLM, ORG, and $\mathrm{TKB}$ ) as the exogenous variables on MP and SERVQUAL as the endogenous variables were investigated in the structural model (i.e., H1 to H8). The effect of service quality (SERVQUAL) on the marketing performance (MP) was also examined (i.e., H9), significantly from zero at the 0.05 significance level (one-tailed), with the existing 0.000 for a $p$-value $<0.05$. The results of the hypotheses were as follows: the first relationship stated the impact of KCF on MP (T-value = 4.969; St, B =0.343; $p$-value $=0.000)$, the second relationship was between KLM and MP (T-value $=2.297$; $\mathrm{St}, \mathrm{B}=0.128$; $p$-value $=0.002$ ), and the third relationship was between ORG and MP (T-value $=2.032$; St, B $=-0.095$; $p$-value $=0.043$ )

As for the fourth relationship between TKB and MP, the result was T-value $=3.11$, St, $\mathrm{B}=0.189$, and $p$-value $=0.002$. In addition, the fifth relationship was between $\mathrm{KFC}$ and SERVQUAL, and the result was T-value $=4.829 ; \mathrm{St}, \mathrm{B}=0.388$; and $p$-value $=0.000$. Meanwhile, the sixth relationship was between KLM and SERVQUAL (T-value = 3.273; St, $\mathrm{B}=0.221 ; p$-value $=0.001)$, and the seventh relationship was between ORG and SERVQUAL $(\mathrm{T}$-value $=2.652 ; \mathrm{St}, \mathrm{B}=-0.167 ; p$-value $=0.008)$. Likewise, the eighth relationship was between TKB and SERVQUAL, and the result was T-value $=2.572$; St, B =0.184; and $p$-value $=0.010$. Finally, the last direct relationship was between SERVQUAL and MP as well $(\mathrm{T}$-value $=4.471 ; \mathrm{St}, \mathrm{B}=0.292 ; p$-value $=0.000)$. From all of the above, the results of the study implied that all of the hypotheses were in a direct relationship $(\mathrm{H} 1, \mathrm{H} 2, \mathrm{H} 4, \mathrm{H} 5, \mathrm{H} 6$, H8, H9), except H3 and H7, which were not supported because of the St, B, which meant they were negative. 
Table 6. The results of the hypothesis testing (direct effect).

\begin{tabular}{|c|c|c|c|c|c|c|c|}
\hline $\mathrm{Ha}$ & Path & $\beta$ & Std. Dev & T-Value & $p$-Value & VIF & Decision \\
\hline H1 & $\mathrm{KCF}->\mathrm{MP}$ & 0.343 & 0.069 & 4.969 & 0.000 & 3.465 & Supported \\
\hline $\mathrm{H} 2$ & KLM -> MP & 0.128 & 0.056 & 2.297 & 0.002 & 2.512 & Supported \\
\hline H3 & ORG -> MP & -0.095 & 0.047 & 2.032 & 0.043 & 1.127 & $\begin{array}{c}\text { Not } \\
\text { Supported }\end{array}$ \\
\hline $\mathrm{H} 4$ & $\mathrm{TKB}->\mathrm{MP}$ & 0.189 & 0.061 & 3.110 & 0.002 & 2.247 & Supported \\
\hline H5 & KCF -> SERVQUAL & 0.388 & 0.080 & 4.829 & 0.000 & 3.156 & Supported \\
\hline H6 & KLM -> SERVQUUAL & 0.221 & 0.067 & 3.273 & 0.001 & 2.412 & Supported \\
\hline H7 & ORG -> SERVQUAL & -0.167 & 0.063 & 2.652 & 0.008 & 1.070 & $\begin{array}{c}\text { Not } \\
\text { Supported }\end{array}$ \\
\hline H8 & TKB -> SERVQUAL & 0.184 & 0.071 & 2.572 & 0.010 & 2.178 & Supported \\
\hline H9 & SERVQUAL -> MP & 0.292 & 0.065 & 4.471 & 0.000 & 2.050 & Supported \\
\hline
\end{tabular}

The current study also examined the indirect effect of the exogenous variable on the endogenous variable through the mediating variable (Preacher and Hayes, 2008) by using bootstrapping. The results of the mediation analysis are presented in Table 4, and are discussed below.

Table 7 indicates that mediating effects of SERVQUAL on the effects KCF, KLM, ORG, and TKB, as the independent variables on MP were determined using mediation analysis. The mediating effects that were tested were represented by hypotheses H10 to H13. In the study, the results of the bootstrapping indicated that the indirect effect of KCF on MP through SERVQUAL (H10) was statistically significant at the 0.05 level; $\beta=0.113$, $\mathrm{t}$-value $=3.195, p$-value $=0.001$. Furthermore, the bias-corrected confidence interval $(\mathrm{CI})$ did not straddle a 0 in-between the lower level $(\mathrm{LL}=0.047)$ and the upper level $(\mathrm{UL}=0.184)$, which indicated that $\mathrm{H} 10$ was supported. Likewise, the indirect effect of KLM on MP through SERVQUAL was statistically significant at the 0.05 level: $\beta=0.064$, $\mathrm{t}$-value $=2.381, p$-value $=0.018$ and the bias-corrected confidence interval $(\mathrm{CI})$ did not straddle a 0 in-between the lower level ( $L L=0.023)$, upper level $(\mathrm{UL}=0.126)$, which indicated that $\mathrm{H} 11$ was supported. The same result came out in the indirect effect of ORG on MP through SERVQUAL, which was statistically significant at the 0.05 level: $\beta=-0.049$, $\mathrm{t}$-value $=2.20, p$-value $=0.028$, where the bias-corrected confidence interval (CI) did not straddle a 0 in-between the lower level (LL $=-0.087$ ) and the upper level $(\mathrm{UL}=-0.002)$; this means H12 was supported. Eventually, the indirect effect of TKB on MP through SERVQUAL was positive and statistically significant at the 0.05 level: $\beta=0.054$, $\mathrm{t}$-value $=2.412, p$-value $=0.016$, and the bias-corrected confidence interval $(\mathrm{CI})$ did not straddle a 0 in-between the lower level $(\mathrm{LL}=0.018)$ and the upper level $(\mathrm{UL}=0.103)$; this implied that H14 was supported.

Table 7. The results of the hypothesis testing for the mediating role of SERQUAL.

\begin{tabular}{|c|c|c|c|c|c|c|c|c|}
\hline HYP & Path & $\beta$ & Std. Dev & T-Value & $p$-Value & LL $2.5 \%$ & UL $97.5 \%$ & Decision \\
\hline H10 & KCF -> SERVQUAL -> MP & 0.113 & 0.035 & 3.195 & 0.001 & 0.047 & 0.184 & Supported \\
\hline H11 & KLM -> SERVQUAL -> MP & 0.064 & 0.027 & 2.381 & 0.018 & 0.023 & 0.126 & Supported \\
\hline H12 & ORG -> SERVQUAL -> MP & -0.049 & 0.022 & 2.200 & 0.028 & -0.087 & -0.002 & Supported \\
\hline H13 & TKB -> SERVQUAL -> MP & 0.054 & 0.022 & 2.412 & 0.016 & 0.0018 & 0.103 & Supported \\
\hline
\end{tabular}

\section{Discussion}

Regarding the impact of key customer focus, the results of the current study revealed that it had a positive, direct, significant impact on marketing performance; thus, H1 was supported. This result is in line with previous studies that indicated that key customer focus plays a key role in improving marketing performance $[27,43,55]$. Therefore, the service provider must focus on key customers to provide them with good service, products and attention, and thereby improve customer satisfaction. Such customers will then return, and this will consequently increase the profits and overall marketing performance of the hotel. With regard to the relationship between CRM knowledge management and 
marketing performance, the results revealed that knowledge management had a positive, direct, significant impact on marketing performance, and thus $\mathrm{H} 2$ was supported. This result is in line with Raeeszadeh, Gilaninia and Homayounfar [46]; Almotairi [49]; and Kianto, Hussinki and Vanhala [48], who observed that there is a positive association between CRM knowledge management and marketing performance. In detail, the findings imply that hotels or other organizations that have access to customers' information and translate it into useful knowledge will experience an increase in their ability to enhance their marketing performance.

In the relationship between CRM organization and marketing performance, the effect was negative, direct and significant. Hence, $\mathrm{H} 3$ was not supported. The possible justifications could be because (1) of the lack of expertise and resources to run CRM effectively in some Jordanians hotels, which then leads to poor marketing performance; or (2) some training programmes to develop skills for acquiring and deepening customer relationships that were conducted by hotels have not been able to enhance the hotels' employee's ability to enhance the customer relationship. Based on the assumption in $\mathrm{H} 4$ in which it was hypothesized that technology-based CRM has a positive impact on marketing performance, the finding of the study also supported $\mathrm{H} 4$. Thus, this result was also supported by previous studies such as the studies performed by Al-Adamat [10] and Almotairi [49].

In depth, this means that when the management of an organization such as a hotel improves their IT systems and renews CRM tools and techniques, this will lead to an increased market share, and will consequently raise the marketing performance level. In $\mathrm{H} 5$, it was hypothesized that key customer focus has a positive impact on service quality, and thus $\mathrm{H} 5$ is supported. This result supports prior studies that came out by Ghandour, Deans and Benwell [65] in which the authors mentioned that when an organization focuses on its customers, this helps the organization to obtain their views on products or services. Not only that, the organization also will have the opportunity to introduce those services and products, whether tangible or intangible, which will then act as a medium of conveying the best image of the organization.

In H6, it was hypothesized that CRM knowledge management has a positive impact on service quality. Hence, $\mathrm{H} 6$ is supported. This result is in line with the argument of Torbati, Jokar and Liravi [69], where the authors uncovered that this can inspire hoteliers to obtain important information about customers and/or competitors, as it is possible to benefit from this information and turn it into useful and real knowledge to raise up the service quality. Regarding the influence of CRM organization on service quality, the study found that CRM organization had a negative direct significant impact on service quality; thus, H7 was not supported.

The possible justifications for why H7 was not supported could be due to the reason that the hotels' employee's performance does not meet the customers' expectations. It is probable that some of the hotel's employees were not clear about the hotel's goals on customer acquisition. The impact of technology-based CRM on service quality was positive, and thus H8 was supported. This result is also in line with Bresnahan [101]. Studies by Foya, Kilika, Muathe and Herman Foya [77], and Hsieh [102] showed that if a hotel institution develops its IT and the technological tools related to CRM and its operation, this will increase the quality of services. In $\mathrm{H} 9$, it was hypothesized that service quality has a positive impact on marketing performance. This result is in line with Akroush [81], where the author confirmed that the attention to the components and elements of service quality, and their improvement, will help hotels to improve their marketing performance.

The mediating effect of service quality between key customer focus, CRM knowledge management, CRM organization, and technology-based CRM will be given next. In H10 it was hypothesized that the service quality mediates the relationship between key customer focus and marketing performance. Meanwhile, this study also showed that the existence of service quality as a mediator between key customer focus and marketing performance led to a significant relationship, and thus $\mathrm{H} 10$ was supported. In this finding, the service quality 
could act as a remarkable indicator in the goal to achieve superior marketing performance, especially if hotels wanted to focus on key customers by raising the quality of service.

In H11, it was hypothesized that service quality mediates the relationship between CRM knowledge management and marketing performance, and this study found that the existence of service quality as a mediator between CRM knowledge management and marketing performance led to a significant relationship. This result implies that a service quality strategy is important as it can help to support and bolster the relationship between CRM knowledge management and marketing performance.

In H12, it was hypothesized that service quality mediates the relationship between CRM organization and marketing performance. This investigation showed that service quality acted as a mediator in this relationship; hence, service quality is a crucial factor in achieving superior marketing performance. Furthermore, it has been argued that if an organization instils customer relationship values in its organizational culture and puts those values into practice, it can satisfy the needs of the customers by raising the quality of its services. In H13, it was hypothesized that service quality mediates the relationship between key customer focus and marketing performance. This study found that service quality mediated the relationship between CRM-based technology and marketing performance, implying that the service quality strategy is a suitable managerial strategy to be applied in hotels when they are seeking to understand and enhance the relationship between CRM-based technology and marketing performance.

\section{Conclusions}

Understanding factors influencing marketing performance in the context of the hotel industry is crucial, as this industry is very competitive. Understanding how technology and the innovation of service quality would help hotels to enhance their performance and gain sustainable competitive advantage is also crucial. This study employed RBV theory and contingency theory to examine the CRM performance dimensions (key customer focus, CRM knowledge management, CRM organization, and technology-based CRM) regarding marketing performance in the context of the hotel industry in Jordan. It also examined the mediating role of service quality in the relationship between these CRM performance dimensions and marketing performance.

From the findings and discussion presented herein, it would seem clear that this study made a significant contribution by providing an increased understanding of the influence of CRM performance dimensions on marketing performance, as well as the mediating role of service quality on that relationship in the context of the hotel industry in Jordan, which has to date received very little interest in the literature. The results of this study contributed to bridging the gap in the literature, as most of the past studies focused on the hotel sector in developed countries. Indeed, this study paves the way to the extension of research on CRM and service quality in the context of Middle Eastern countries. This study provides an enhanced understanding of the influence of CRM performance dimensions on marketing performance, as well as the mediating role of service quality on that relationship in the context of developing countries. Thus, in the competitive hotel industry, upgrading service quality is crucial in order to enhance marketing performance, as well as to gain a competitive advantage.

This study used PLS-SEM 3.2.8 path coefficients to test the research hypotheses regarding the relationships among the CRMP dimensions (key customer focus, CRM organization, CRM knowledge management, and CRM-based technology), service quality, and marketing performance in hotels. The findings showed that three of the CRMP dimensions (key customer focus, CRM knowledge management, and CRM-based technology) had a positive and significant impact on marketing performance, whereas CRM organization had a negative impact on marketing performance. Similarly, three CRMP dimensions (key customer focus, CRM knowledge management, and CRM-based technology) had a positive and significant impact on service quality, whereas CRM organization had a negative impact on service quality. In addition, service quality was found to have a positive and signif- 
icant influence on marketing performance. The study also revealed that service quality played a mediating role in the relationship between CRMP dimensions (key customer focus, CRM organization, CRM knowledge management, and CRM-based technology) and marketing performance in hotels. Thus, in an industry that is extremely competitive, service quality clearly has a crucial role to play in improving marketing performance through the application of CRM dimensions (key customer focus, CRM organization, CRM knowledge management, and CRM-based technology). Furthermore, this study highlights the theoretical and practical contributions.

\subsection{Theoretical Implications}

The current study makes three major theoretical contributions. First, it was apparent from the review of the literature that the impact of customer relationship management performance dimensions (key customer focus, CRM organization, CRM knowledge management, and CRM-based technology) on marketing performance was still unclear. Therefore, this study significantly contributes to the literature because it is a pioneering study that examines the impact of each dimension of CRM performance (key customer focus, CRM organization, CRM knowledge management, and CRM-based technology) on marketing performance. Second, this study filled the gap in the knowledge that was identified in previous studies $[27,33,37,43,49,103]$ regarding the effects of CRM on marketing performance in the hotel sector, by revealing that the CRMP dimensions (key customer focus, CRM organization, CRM knowledge management, and technology-based CRM) do have a relationship with marketing performance in the hotel sector.

Second, this study employed the integrated RBV and contingency theory as a theoretical framework, which to the knowledge of the authors has not been used before in the past studies on CRM and service quality. Second, this study employs the integrated RBV and contingency theory as a theoretical framework, which to the knowledge of the authors has not been used before in the past studies on CRM and service quality. The current study contributed in terms of combining the perceptions of RBV theory and contingency theory through the application of the environment factor, including capability resources, in order to find a way for hotels to achieve superior performance. Hence, this study provides support towards RBV theory in the context of the hotel industry.

Finally, this study examined the mediating role of service quality on the relationship between the CRMP dimensions (key customer focus, CRM knowledge management, CRM organization, and CRM-based technology) and marketing performance. This study confirmed the mediating role of service quality in the relationship between CRMP dimensions (key customer focus, CRM knowledge management, CRM organization, and CRM-based technology) and marketing performance, which was not clear before. This finding helps to close the gap that was suggested by Akroush, Dahiyat, Gharaibeh and Abu-Lail [33], and Yadav and Singh [20], who suggested that it would be of benefit to investigate the mediating role of service quality in the relationship between CRMP dimensions (key customer focus, CRM knowledge management, CRM organization, and technology-based CRM) and marketing performance.

\subsection{Practical Implications}

The results of these endeavors provide an insight into hotel marketing performance in Jordan from the perspective of the customer relationship management performance dimensions (key customer focus, CRM organization, CRM knowledge management, and technology-based CRM) and service quality aspects. By using the findings reported in this thesis, managers may be able to enhance their hotel's marketing performance, and may thereby guarantee their hotel's continued existence in a highly competitive marketplace. Meanwhile, the study attempted to provide the hotels in Jordan with practical advice and solutions on how to successfully implement CRM by concentrating on four dimensions (key customer focus, CRM organization, CRM knowledge management, and technology-based CRM), and by activating each dimension of CRM performance alone and focusing on each 
one of these dimensions separately. Thus, hotel managers should recognize, first, that in order to carry out CRM performance, managers should pay more attention to their employees. This could be carried out in several ways, including the provision of training, motivation, and the use of a proper reward system.

Besides this, it was also proven that even with modern technology and the bestdefined processes, a CRM strategy still cannot be fully carried out without the engagement of employees. Furthermore, this study emphasized that a key customer focus strategy has an active role to play in enhancing hotel marketing performance. Therefore, managers in classified hotels should guide both the firm and its workers to address the needs and wants of the customers as a top priority. Moreover, the study indicated that hotels (rated hotels) using advanced technology and carrying out processes to acquire, maintain, manage and share customer information would increase the customers' satisfaction. In the long run, this would lead to an expansion of the market share, increased profits and higher marketing performance. Besides this, the study also supplied evidence which stressed that service quality can lead to improved marketing performance in hotels, and that this factor played a key role in the relationship between customer relationship performance dimensions (key customer focus, CRM organization, CRM knowledge management, and CRM-based technology).

\section{Limitations and Suggestions for Future Research}

The first limitation is related to the sample size and unit of analysis. The study only focused on one- to five-star hotels (classified hotels). Therefore, future studies may wish to conduct similar research on both classified and unclassified hotels' general managers, rather than concentrating solely on classified hotels. This could provide a higher response rate and a better understanding of the mediating role of service quality in the relationship between CRMP dimensions (key customer focus, CRM knowledge management, CRM organization, and CRM-based technology) and marketing performance in the hotel industry. Furthermore, future researchers may obtain the customers' responses by examining the effect of service quality on their satisfaction in hotels. Additionally, future studies may wish to test the relationships that were proposed in this study in order to find out if they would be suitable in other countries, sectors and companies, such as the industrial sector, telecommunication companies, and private hospitals.

Secondly, the study used a quantitative approach (primary data) from the managers' perspectives in order to achieve its objectives, because there were difficulties in relation to the accessibility of the hotel's data, which included unauthorized data. Therefore, in order to comprehend the changes that might arise when CRMP dimensions are being carried out on marketing performance through the mediation of the service quality, longitudinal research studies could be undertaken by using another method, such as a qualitative technique, which could be of a use in gaining comprehension on the issues. This would be of help in revealing how hotels can carry out CRMP, and could give an insight on how it could affect the marketing performance through the mediation of the service quality between them effectively.

Third, this study examined the relationships between CRMP dimensions (key customer focus, CRM knowledge management, CRM organization, and CRM-based technology) separately, as well as service quality and marketing performance. It is therefore recommended that future research should investigate other CRM factors that might influence the service quality and marketing performance, such as CRM success factors and operational CRM. Furthermore, the findings of this study indicated that the effect of CRM organization on performance more comprehensively may have a greater effect. This is because it was found that CRM organization had a negative impact on marketing performance and service quality, which was in contrast to the other dimensions of CRM performance (key customer focus, CRM knowledge management, and CRM-based technology), which each had a positive impact on service quality and the marketing performance. 
Fourth, this study only examined the mediating role of service quality on the relationship between CRMP dimensions (key customer focus, CRM organization, CRM knowledge management, and CRM-based technology) and marketing performance. Thus, future research could investigate other factors that might influence the association between CRMP dimensions (key customer focus, CRM organization, CRM knowledge management, and CRM-based technology) and marketing performance, such as the strategic planning.

Author Contributions: Conceptualization, J.A.A.-G., M.M.A. and S.F.P.; methodology, J.A.A.-G., M.M.A. and J.S.; validation, M.M.A., S.F.P., J.S., K.N.A. and A.u.-H.; formal analysis, J.A.A.-G., M.M.A., J.S., K.N.A. and S.F.P.; investigation, J.A.A.-G. and M.M.A.; writing-original draft preparation, J.A.A.-G., M.M.A., J.S., K.N.A. and S.F.P.; writing-review and editing, J.A.A.-G., M.M.A., J.S., K.N.A., S.F.P. and A.u.-H.; supervision, M.M.A. and S.F.P.; project administration, J.A.A.-G., M.M.A., J.S., K.N.A. and S.F.P.; funding acquisition, J.A.A.-G. and K.N.A. All authors have read and agreed to the published version of the manuscript.

Funding: This study was not funded by any agency.

Institutional Review Board Statement: Not applicable.

Informed Consent Statement: Not applicable.

Data Availability Statement: Not applicable.

Acknowledgments: The authors would like to thank Universiti Malaysia Terengganu and Applied Science Private University for supporting this research. We would also like to thank the reviewers for all of the constructive comments.

Conflicts of Interest: The authors declare no conflict of interest.

\section{References}

1. Njoroge, M.; Anderson, W.; Mbura, O. Innovation strategy and economic sustainability in the hospitality industry. Bottom Line 2019, 32, 253-268. [CrossRef]

2. Pasape, L.; Anderson, W.; Lindi, G. Assessment of indicators of sustainable ecotourism in Tanzania. Anatolia 2015, 26, 73-84. [CrossRef]

3. Magno, F.; Cassia, F.; Bruni, A. Adoption and impact of marketing performance assessment systems among travel agencies. Int. J. Contemp. Hosp. Manag. 2017, 29, 1133-1147. [CrossRef]

4. Al-Ababneh, M.M. Employees' perspectives of service quality in hotels. Res. Hosp. Manag. 2016, 6, 189-193. [CrossRef]

5. Zeithaml, V.A.; Berry, L.L.; Parasuraman, A. SERVQUAL: A multiple-item scale for measuring consumer perceptions of service quality. J. Retail. 1988, 64, 12-40.

6. Huang, C.W.; Ho, F.N.; Chen, Y.C. Assessing the Effectiveness of Marketing Strategies in Tourist Hotels: An Illustration Using a Multi-Method Approach in Taiwan. J. Travel Tour. Mark. 2015, 32, S15-S29. [CrossRef]

7. Al-Azzam, A.F.M. The impact of customer relationship management on hotels performance in Jordan. Int. J. Bus. Soc. Sci. 2016, 7, 200-210.

8. Ministry of Tourism Jordan. Statistical Newsletter. 2016. Available online: http://dosweb.dos.gov.jo/DataBank/yearbook/ YearBook2016_eng.pdf (accessed on 15 September 2021).

9. Al-Laymoun, M.R.K. The Impact of Customer Relationship Management on Tourist Satisfaction in Movenpick Resort and Residences in Aqaba, Jordan. Eur. Sci. J. 2016, 12. [CrossRef]

10. Al-Adamat, A. The Impact of Information and Communication Technology on the Marketing Performance of Jordanian Hotels. Ph.D. Thesis, Queen Margaret University, Edinburgh, UK, 2015.

11. Talabi, J. The Role of Marketing in Hotel Industry: Six successful hotel units in Abuja and Jakobstad. Asian J. Manag. 2015, 9 , 39-41.

12. Hammouri, Q.; Al-Gasawneh, J.A.; Nusairat, N.M.; Hanandeh, A.; Barakat, S. The Determinants of Trust and its Influence on Online Buying Intention: An Empirical Study on Social Commerce in Jordan. Ann. Rom. Soc. Cell Biol. 2021, 25, 4522-4539.

13. Pratminingsih, S.A.; Astuty, E.; Widyatami, K. Increasing customer loyalty of ethnic restaurant through experiential marketing and service quality. J. Entrep. Educ. 2018, 21,1-11.

14. Al-Gasawneh, J.A.; Anuar, M.M.; Dacko-Pikiewicz, Z.; Saputra, J. The impact of customer relationship management dimensions on service quality. Pol. J. Manag. Stud. 2021, 23, 24-44. [CrossRef]

15. Abu-Nazir, W.; Jadalla, I.; Naseri, A. Impact of Customer Service Quality on Business Performance in Hospitality Industries: An empirical study. J. Tour. Hosp. Sport. 2016, 17, 10-28.

16. Asgari, M.H.; Omrani, E.M. The relationship between service quality, customer relationship management staff BSI. Int. J. Humanit. Cult. Stud. 2016, 8, 990-1000. 
17. Kangu, M.A. The Role of Customer Relationship Management Dimensions on Customer Loyalty in the Hotel Industry in Kenya Maureen Adhiambo. Ph.D. Thesis, COHRED. JKUAT (Jomo Kenyatta University of Agriculture and Technology), Juja, Kenya, 2017.

18. Al-Gasawneh, J.; Al-Wadi, M.; Al-Wadi, B.; Alown, B.; Nuseirat, N. The Interaction Effect of Comprehensiveness Between Social Media and Online Purchasing Intention in Jordanian Pharmacies. Int. Assoc. Online Eng. 2020, 14, 208-221. [CrossRef]

19. Alshourah, S.; Alassaf, H.; Altawalbeh, M. Roles of Top Management and Customer Orientation in Enhancing the Performance of Customer Relationship Management (CRM) in Hotel Industry. Int. J. 2018, 6, 233-239.

20. Yadav, B.K.; Singh, A. Analyzing the influence of customer relationship management on firm performance: A study of hotel industry in India. Int. J. Cust. Relatsh. Mark. Manag. 2014, 5, 69-97. [CrossRef]

21. Barney, J. Firm resources and sustained competitive advantage. J. Manag. 1991, 17, 99-120. [CrossRef]

22. Conner, K.R. A historical comparison of resource-based theory and five schools of thought within industrial organization economics: Do we have a new theory of the firm? J. Manag. 1991, 17, 121-154. [CrossRef]

23. Amit, R.; Schoemaker, P.J. Strategic assets and organizational rent. Strateg. Manag. J. 1993, 14, 33-46. [CrossRef]

24. Campbell, A.; Luchs, K.S. Core Competency-Based Strategy; Cengage Learning Business Press: London, UK, 1997.

25. Luthans, F.; Stewart, T.I. A general contingency theory of management. Acad. Manag. Rev. 1977, 2, 181-195. [CrossRef]

26. Sirmon, D.G.; Hitt, M.A.; Ireland, R.D.; Gilbert, B.A. Resource orchestration to create competitive advantage: Breadth, depth, and life cycle effects. J. Manag. 2011, 37, 1390-1412. [CrossRef]

27. Albakri, T.; Hadi, A. The impact on the customer relationship marketing performance management (Analytical study on a sample of Jordanian commercial banks). Mag. Coll. Adm. Econ. Adm. Financ. Stud. 2014, 6, 1-35.

28. Martensen, A.; Grønholdt, L. Internal marketing: A study of employee loyalty, its determinants and consequences. Innov. Mark. 2006, 2, 92-116.

29. Drohan, R.; Lynch, P.; Foley, A. Utilising the resource-based view (RBV) to enhance CRM practices in Irish Hotels. Manag. Sci. 2009, 19, 150-151.

30. Zineldin, M. The royalty of loyalty: CRM, quality and retention. J. Consum. Mark. 2006, 23, 430-437. [CrossRef]

31. Madhovi, P.G.; Dhliwayo, S. The relationship between customer relationship management (CRM) and performance in the hotel industry. Afr. J. Hosp. Tour. Leis. 2017, 6, 1-13.

32. Vallabh, D.; Radder, L.; Venter, D. Factors preceding CRM readiness in small-and medium-sized tourism enterprises. Acta Commer. 2015, 15, 1-9. [CrossRef]

33. Akroush, M.N.; Dahiyat, S.E.; Gharaibeh, H.S.; Abu-Lail, B.N. Customer relationship management implementation: An investigation of a scale's generalizability and its relationship with business performance in a developing country context. Int. J. Commer. Manag. 2011, 11, 92-101. [CrossRef]

34. Boateng, I.A. Effect of customer relationship management on the performance of banking services in ghana. J. Contemp. Integr. Ideas 2012, 2, 13-25.

35. Benedettini, O.; Swink, M.; Neely, A. Examining the influence of service additions on manufacturing firms' bankruptcy likelihood. Ind. Mark. Manag. 2017, 60, 112-125. [CrossRef]

36. Soliman, H.S. Customer relationship management and its relationship to the marketing performance. Int. J. Bus. Soc. Sci. 2011, 2, 166-182.

37. Shaaban, M.N.; Ghoneim, S.A. Assessing the Effect of Customer Relationship Management on Hotels' Marketing Performance: The Mediating Role of Marketing Capabilities-Evidence from Sharm El-Sheikh, Egypt. Tour. Res. Inst. 2017, 18, 84-104.

38. Ewnetu, S. The Impact of Customer Relationship Management on Marketing Performance of Commercial Bank of Ethiopia. Ph.D. Thesis, St. Mary's University, Calgary, AB, Canada, 2015.

39. Ibrahim, R.Z.A.R.; Saputra, J.; Akmal, N.A. The Effects of Work-Family Conflict on Teachers' Job Satisfaction: A Study in the East Coast of Malaysia. Int. J. Innov. Creat. Chang. 2020, 13, 542-556.

40. Yaacob, Z. The direct and indirect effects of customer focus on performance in public firms. Int. J. Qual. Res. 2014, 8, 265-276.

41. Arifin, A.H.; Saputra, J.; Puteh, A.; Qamarius, I. The role of organizational culture in the relationship of personality and organization commitment on employee performance. Int. J. Innov. Creat. Chang. 2019, 9, 105-129.

42. Nwokah, N.G. Customer-focus, competitor-focus and marketing performance. Meas. Bus. Excell. 2009, 13, 20-28. [CrossRef]

43. Gebeyehu, J. Effects of Customer Relationship Management on Market Performance: A Comparative Perspective. Ph.D. Thesis, Mekelle University, Tigray, Ethiopia, 2014.

44. Sin, L.Y.; Alan, C.B.; Yim, F.H. CRM: Conceptualization and scale development. Eur. J. Mark. 2005, 13, 1264-1290. [CrossRef]

45. Namjoyan, M.; Esfahani, A.N.; Haery, F.A. Studying the effects of customer relationship management on the marketing performance (Isfahan Saderat Bank as a case study). Int. J. Acad. Res. Bus. Soc. Sci. 2013, 3, 302. [CrossRef]

46. Raeeszadeh, S.F.; Gilaninia, S.; Homayounfar, M. The effects of knowledge management components on marketing performance: A case study of educational centers located across Guilan province. Kuwait Chapter Arab. J. Bus. Manag. Rev. 2016, 5, 23. [CrossRef]

47. Jamil, M.Y. Role of Knowledge Management in Achieving Organizational Performance: Proposed Framework through Literature Survey. J. Bus. Econ. Financ. 2017, 6, 125-133. [CrossRef]

48. Kianto, A.; Hussinki, H.; Vanhala, M. The impact of knowledge management on the market performance of companies. In Knowledge Management in the Sharing Economy; Springer: Cham, Switzerland, 2018; pp. 189-207. 
49. Almotairi, M. A framework for successful CRM implementation. In Proceedings of the European and Mediterranean Conference on Information Systems, Izmir, Turkey, 13-14 July 2009; pp. 1-14.

50. Chang, Y.; Wang, X.; Arnett, D.B. Enhancing firm performance: The role of brand orientation in business-to-business marketing. Ind. Mark. Manag. 2018, 72, 17-25. [CrossRef]

51. Ahmad, F. Knowledge sharing in a non-native language context: Challenges and strategies. J. Inf. Sci. 2018, 44, 248-264. [CrossRef]

52. Alghasawneh, L.A.S.; Akhorshaideh, A.H.; Alharafsheh, M.; Ghasawneh, A.; Al-Gasawneh, J.A.; Al-Hadid, A.Y. Determinants of Supply Chain Management Practices in Jordanian Pharmaceutical Firms. Solid State Technol. $2021,64,2986-3001$.

53. Masa'deh, R.E.; Almajali, D.A.; Alrowwad, A.A.; Obeidat, B. The role of knowledge management infrastructure in enhancing job satisfaction: A developing country perspective. Interdiscip. J. Inf. Knowl. Manag. 2019, 14, 1-25. [CrossRef]

54. Mohammed, A.A.; Rashid, B. Customer Relationship Management (CRM) in Hotel Industry: A framework proposal on the relationship among CRM dimensions, Marketing Capabilities, and Hotel performance. Int. Rev. Manag. Mark. 2012, 2, 220.

55. Wali, A.F.; Wright, L.T.; Nwokah, N.G.; Reynolds, P.L. Customer relationship management and service quality: A qualitative study. J. Compet. 2015, 6, 50-53.

56. Alghamdi, S.; Bach, C. Technological Factors to Improve Performance of Marketing Strategy. In Proceedings of the ASEE 2014 Zone I Conference, Bridgeport, CT, USA, 3-5 April 2014; pp. 3-5.

57. Sunny, E.E.; Abolaji, O.S. Electronic Customer Relationship Management (E-CRM) \& Marketing Performance: Empirical Evidence from Nigeria Telecom Sector. J. Econ. Manag. Trade 2016, 11, 1-14.

58. Bowie, D.; Paraskevas, A.; Mariussen, A. Technology-driven online marketing performance measurement: Lessons from affiliate marketing. Int. J. Online Mark. 2014, 4, 1-16. [CrossRef]

59. Ginanjar, I.R.; Hurriyati, R.; Adiwibowo, L.; Gaffar, V.; Saputra, J. The Role of Supply Chain Management Consumer Attitude as Intervening between Brand Images, Perceived Value and Revisiting Intention. Int. J. Sup. Chain. Mgt. 2019, 8,901.

60. Allon, G.; Babich, V. Crowdsourcing and crowdfunding in the manufacturing and services sectors. Manuf. Serv. Oper. Manag. 2020, 22, 102-112. [CrossRef]

61. Wali, A.F.; Uduma, I.A.; Wright, L.T. Customer relationship management (CRM) experiences of Business-to-Business (B2B) marketing firms: A qualitative study. Cogent Bus. Manag. 2016, 3, 1183555. [CrossRef]

62. Ryding, D. The impact of new technologies on customer satisfaction and business to business customer relationships: Evidence from the soft drinks industry. J. Retail. Consum. Serv. 2010, 17, 224-228. [CrossRef]

63. Ngo, V.M.; Nguyen, H.H. The relationship between service quality, customer satisfaction and customer loyalty: An investigation in Vietnamese retail banking sector. J. Compet. 2016, 8, 103-116.

64. Irfan, S.M.; Kee, D.M.H. Critical success factors of TQM and its impact on increased service quality: A case from service sector of Pakistan. Middle-East J. Sci. Res. 2013, 15, 61-74.

65. Ghandour, A.; Deans, K.R.; Benwell, G.L. The impact of customer focus to the success of eCommerce systems among small and medium enterprises-A conceptual framework. In Proceedings of the Australian and New Zealand Marketing Academy 2007 Conference (ANZMAC 2007), Dunedin, New Zealand, 3 December 2007.

66. Abd Rahim Romle, A.H.; Zakaria, M.Z.S.; Zakinuddin, S.N.; Zolkepli, M.S.H.; Daud, R. The effects of TQM practices on organizational culture: A new movement. World Appl. Sci. J. 2016, 34, 553-560.

67. Azhar, S. The relationship between customer knowledge and customer relationship management towards service quality in Malaysia. SSRN 2015, 1-20. [CrossRef]

68. Lo, A.S.; Stalcup, L.D.; Lee, A. Customer relationship management for hotels in Hong Kong. Int. J. Contemp. Hosp. Manag. 2010, 22, 139-159. [CrossRef]

69. Torbati, S.E.; Jokar, I.; Liravi, E. The Role of Knowledge Management Customer-Oriented Approach on Enhancing Service Quality; Case Study: Three Large Private Hospitals in Shiraz. Indian J. Fundam. Appl. Life Sci. 2014, 4, $208-215$.

70. Goldman, N.C.; Harris, M.; Omer, T.C. Does task-specific knowledge improve audit quality: Evidence from audits of income tax accounts. Int. Financ. J. 2019, 11, 91-106. [CrossRef]

71. Khafajy, N.A.; Alzoubi, H.M.; Aljanabee, A.K. Analyzing the Effect of Knowledge Management Processes in The Services' Quality in Iraqi Commercial Banks. Int. Rev. Manag. Bus. Res. 2016, 5, 302.

72. Pasebani, F.; Mohammadi, S.; Yektatyar, M. The relationship between organizational learning culture and job satisfaction and internal service quality in sport organizations in Iran. Arch. Appl. Sci. Res. 2012, 4, 1901-1905.

73. Habidin, N.F.; Ali, N.; Janudin, S.E.; Zainol, Z.; Mustaffa, W.S.W.; Hudin, N.S. Customer Relationship Management and Service Quality Improvement in Malaysian Healthcare Industry. Int. J. Pharm. Sci. Rev. Res. 2015, 35, $203-209$.

74. Kotler, P.; Armstrong, G. Principles of Marketing, 11th ed.; Printice Hall: Upper Saddle River, NJ, USA, 2006.

75. Collier, J.E.; Bienstock, C.C. Measuring service quality in e-retailing. J. Serv. Res. 2006, 8, 260-275. [CrossRef]

76. Ombati, T.O.; Magutu, P.O.; Nyamwange, S.O.; Nyaoga, R.B. Technology and service quality in the banking industry. Afr. J. Bus. Manag. 2010, 1, 1-14.

77. Foya, A.H.; Kilika, J.; Muathe, S.; Herman Foya, A. Relating technology based CRM to service quality in the telecommunications industry in Arusha city, Tanzania. Sci. J. Bus. Manag. 2015, 3, 209-218. [CrossRef]

78. Malkawi, A.F. The Impact of the Use of Information Technology in Improving the Quality of Services: A Field Study of Fast-Food Restaurants in Jordan. Eur. Sci. J. ESJ 2017, 13, 359. [CrossRef] 
79. Bowie, D.; Buttle, F.; Brookes, M.; Mariussen, A. Hospitality Marketing; Routledge: London, UK, 2016.

80. Chumpitaz, R.; Paparoidamis, N.G. Service quality and marketing performance in business-to-business markets: Exploring the mediating role of client satisfaction. Manag. Serv. Qual. An Int. J. 2004, 14, 235-248. [CrossRef]

81. Akroush, M.N. The effect of service quality on banks marketing performance: An empirical investigation of managers perspectives. Dirasat. Adm. Sci. 2008, 35, 199-218.

82. Ferreira, J.; Fernandes, C. Resources and capabilities' effects on firm performance: What are they? J. Knowl. Manag. 2017, 3, 299. [CrossRef]

83. Newbert, S.L. Empirical research on the resource-based view of the firm: An assessment and suggestions for future research. Strateg. Manag. J. 2007, 28, 121-146. [CrossRef]

84. Baron, R.M.; Kenny, D.A. The moderator-mediator variable distinction in social psychological research: Conceptual, strategic, and statistical considerations. J. Pers. Soc. Psychol. 1986, 51, 1173. [CrossRef] [PubMed]

85. Osarenkhoe, A.; Birungi Komunda, M.; Mbiito Byarugaba, J. Service quality as a mediator of customer complaint behaviour and customer loyalty. Int. Rev. Manag. Mark. 2017, 7, 197-208.

86. Akroush, M.N. Does service quality implementation mediate the relationship between technical service quality and performance: An empirical examination of banks in Jordan. Int. J. Serv. Econ. Manag. 2009, 1, 209-232. [CrossRef]

87. Manohar, S. Mediation effect of service quality between service innovation and customer word-of-mouth in Indian higher education system. Int. J. Bus. Excell. 2018, 16, 127-148. [CrossRef]

88. Sekaran, U.; Bougie, R. Research Methods for Business: A Skill Building Approach; John Wiley \& Sons: Haddington, Scotland, 2019.

89. Chang, H.H.; Ku, P.W. Implementation of relationship quality for CRM performance: Acquisition of BPR and organisational learning. Total Qual. Manag. 2009, 20,327-348. [CrossRef]

90. Alotaibi, S.R.D.; Roussinov, D. Using GPower software to determine the sample size from the pilot study. In Proceedings of the 9th Saudi Students Conference, Birmingham, UK, 13 February 2016.

91. Hair, J.F.; Black, W.C.; Babin, B.J.; Anderson, R.E.; Tatham, R. Multivariate data analysis. In Uppersaddle River; Pearson Prentice Hall: Upper Saddle River, NJ, USA, 2006.

92. Christine, D.; Devie, W.; Tarigan, J. The impact of employee satisfaction on profitability in fashion retail business in Indonesia. World Appl. Sci. J. 2015, 33, 1533-1538.

93. Omar, M. Elements of marketing innovation and its impact on marketing performance/exploratory study on a sample of individuals working a number of commercial companies in the city of Zakho. Humanit. J. Univ. Zakho 2018, 6, 870-888. [CrossRef]

94. Akroush, M.N.; Al-Mohammad, S.M.; Odetallah, A.L. A multidimensional model of marketing culture and performance: A different approach to the use of Webster's marketing culture measurement scale. Int. J. Contemp. Hosp. Manag. 2015, 27, 1442-1478. [CrossRef]

95. Brislin, R.W. Back-translation for cross-cultural research. J. Cross. Cult. Psychol. 1970, 1, 185-216. [CrossRef]

96. Bernard, H.R. Research Methods in Anthropology: Qualitative and Quantitative Approaches; Rowman \& Littlefield: London, UK, 2017.

97. Becker, J.M.; Klein, K.; Wetzels, M. Hierarchical latent variable models in PLS-SEM: Guidelines for using reflective-formative type models. Long Range Plann. 2012, 45, 359-394. [CrossRef]

98. Hair, J.F.; Risher, J.J.; Sarstedt, M.; Ringle, C.M. When to use and how to report the results of PLS-SEM. Eur. Bus. Rev. 2019, 31, 2-24. [CrossRef]

99. Henseler, J.; Ringle, C.M.; Sarstedt, M. A new criterion for assessing discriminant validity in variance-based structural equation modeling. J. Acad. Mark. Sci. 2015, 43, 115-135. [CrossRef]

100. Chin, W.W. How to write up and report PLS analyses. In Handbook of Partial Least Squares; Springer: Berlin/Heidelberg, Germany, 2010; pp. 655-690.

101. Bresnahan, T.F. Computerisation and wage dispersion: An analytical reinterpretation. Econ. J. 1999, 109, 390-415. [CrossRef]

102. Hsieh, Y.C.J. Hotel companies' environmental policies and practices: A content analysis of their web pages. Int. J. Contemp. Hosp. Manag. 2012, 24, 97-121. [CrossRef]

103. Sirbel, M.; Al-Rubaiee, L. The Effect of Information Technology (IT) Capabilities and Customer Relationship Management (CRM) on Marketing Performance: An Empirical Study on Commercial Jordanian Banks in Amman; Middle East University: Amman, Jordan, 2012. 